\title{
DEXA Çekimlerinde Tc-99m Radyonüklidinin Gama Işınlarının Kemik Mineral Yoğunluğu Ölçümlerine Etkisi: Fantom Çalışması
}

\section{The Effect of Gamma Rays Emitted from Tc-99m on Bone Mineral Density Measured by DEXA Scans: Phantom Study}

\author{
Nazenin İpek Işı1kc1 ${ }^{1 *}$, Mustafa Demir ${ }^{2}$ \\ ${ }^{1}$ Nişantaşı Üniversitesi Mühendislik ve Mimarlık Fakültesi, İstanbul, Türkiye \\ 2 İstanbul Üniversitesi-Cerrahpaşa Cerrahpaşa Tıp Fakültesi, İstanbul, Türkiye \\ e-mail: nazeninipek@nisantasi.edu.tr,demirm@istanbul.edu.tr \\ ORCID: 0000-0003-2337-2598 \\ ORCID: 0000-0002-9813-1628 \\ *Sorumlu yazar/ Corresponding Author: Nazenin İpek Işıkcı \\ Gönderim Tarihi / Received: 10.07.2020 \\ Kabul Tarihi / Accepted: 20.11.2020 \\ DOI: $10.34087 /$ cbusbed. 767843

\section{$\ddot{\mathbf{O z}}$}

Giriş ve Amaç: Bu çalışmada, aynı gün içinde aynı hastaya kemik sintigrafisi ve kemik yoğunluğu ölçümlerinin yapılabilme koşullarının araştırılması amaçlandı.

Gereç ve Yöntemler: Çift X-1şınlı Absopsiyometri (DEXA) çekimlerinde, lomber L1-L4 vertebraları taklit eden DEXA kalite kontrol fantomu ve içi su dolu bir tank kullanıldı. Su tankı içine 0.5-4.5 mCi (37-166.5 MBq) arasında değişen aktivite miktarlarında Tc-99m radyoizotopu konuldu. DEXA çekimlerinin birinci aşamasında saçılmasız hava ortamında sadece kalite kontrol fantomunun görüntüsü alındı. İkinci aşamada su tankının üzerine kalite kontrol fantomu konuldu. Aynı geometrik koşullarda farklı Tc-99m aktiviteleri etkisinde 9 adet çekim yapıldı. Çekimlerden kemik mineral yoğunlukları (KMY) hesaplandı.

Bulgular: Saçılmasız ortamda alınan ortalama KMY değeri $1.011 \mathrm{gr} / \mathrm{cm}^{2}$ bulundu. Saçılmalı ortamda farkl1 Tc-99m aktiviteleri etkisinde ölçülen KMY değerlerinin ortalamaları $\left(\mathrm{gr} / \mathrm{cm}^{2}\right)$ : L1: $0.98 \pm 0.01, \mathrm{~L} 2: 1.00 \pm 0.02, \mathrm{~L} 3: 1.02 \pm 0.02$ ve L3: $1.06 \pm 0.02$ bulundu.

Sonuç: Çekim sonuçlarına göre; Tc-99m radyonüklidinin KMY ölçümlerine önemli bir etkisinin bulunmadığı, aynı gün içinde hem kemik sintigrafisinin hem de DEXA çekiminin yapılabileceği belirlendi.

Anahtar kelimeler: DEXA, Kemik mineral yoğunluğu ölçümü, Kemik sintigrafisi, Tc-99m MDP.

\section{Abstract}

Objective: The aim of this study was to investigate the possibility of performing bone scintigraphy with Tc-99m and bone density scan at the same day.

Material and Methods: Dual energy X-ray absorptiometry (DEXA) quality control phantom with imitating lumbar vertebrae L1-L4 and water-filled tank were used in DEXA scan. Tc-99m was injected in the water tank with varying amounts of activity between $0.5-4.5 \mathrm{mCi}$ (37-166.5 MBq). In the first DEXA scan, only the quality control phantom was imaged in a scatter free environment. Then, the quality control phantom was placed on the water tank containing different Tc-99m activities and 9 scans were acquired under the same geometric conditions. Bone mineral density (BMD) was calculated from the acquired scans.

Results: The average BMD value in the non-scattering environment was $1.011 \mathrm{~g} / \mathrm{cm} 2$. The BMD measurements in the scattering environment with different Tc-99m activities were: L1: 0.98 \pm 0.01 , L2: 1.00 \pm 0.02, L3: $1.02 \pm 0.02$ and L4: $1.06 \pm 0.02 \mathrm{gr} / \mathrm{cm}^{2}$.

Conclusion: In consequence, Tc-99m had no significant impact on the BMD measurements, and both bone scintigraphy and DEXA scan can be performed in the same day.

Keywords: Bone mineral density measurement, Bone scintigraphy, DEXA, Tc-99m MDP. 


\section{Giriş}

Klinik olarak kesin sonuçlar vermekte olan ve kemik mineral yoğunluğunu (KMY) kantitatif olarak ortaya koyan Çift X ışını Absorpsiyometri (DEXA) hılı, güvenilir, düşük radyasyonlu ve etkin bir yöntemdir. Kemik mineral yoğunluğu, DEXA yöntemi ile alansal yoğunluk $\left(\mathrm{g} / \mathrm{cm}^{2}\right)$ ölçülür. DEXA yöntemiyle KMY ölçümü osteoporoz tanısında büyük öneme sahiptir. Osteoporoz, kemiklerin kütle kaybetmesine yol açan ve yaygın görülen bir kemik metabolizması hastalığıdır. Osteoporoz değerlendirmelerinde $\mathrm{T}$ ve $\mathrm{Z}$ skorları (istatistiksel bilgiler) üzerinde durulmaktadır. Tedavi değerlendirmesinde ise KMY değerleri kullanılmaktadır $[1,2]$.

DEXA sistemleri $140 \mathrm{keV}$ yüksek enerjili ve $90 \mathrm{keV}$ düşük enerjili olmak üzere iki ayrı enerji seviyesinde $\mathrm{X}$ 1şınları vermektedir. Düşük enerjili ışınlar sadece yumuşak dokuları; yüksek enerjili ışınlar ise yumuşak ve kemik dokusunu geçerek detektöre ulaşmaktadır. İki farklı enerji seviyesindeki X-ışınlarına ait foton atenüasyonu oranları ile kemik ve yağ dokusunun ayrı ayr1 kitleleri hesaplanabilmektedir [3].

Tc-99m radyonüklidi fiziksel özellikleri bakımından Nükleer Tıpta teşhis amacıyla kullanılan en yaygın radyonüklidlerden biri olup $140 \mathrm{keV}$ enerjili monoenerjitik gama radyasyonu yaymaktadır [4].

Çalışmamızda, ${ }^{99 \mathrm{~m}} \mathrm{Tc}$ nin $140 \mathrm{keV}$ 'lik gama DEXA çekimlerindeki sşınlar ile deteksiyon prensipleri göz önüne alınarak etkileşim durumlarının fantom çalışması ile değerlendirilmesi amaçlanmıştır. Fantom çalışması ile kemik sintigrafisi ve kemik yoğunluğu ölçümlerinin aynı hastada aynı gün içinde yapılabilme koşulları araştırılmıştır.

\section{Materyal ve Metot}

Fantom Deney Düzeneği

Çalışmamızda kullandığımız DEXA kalite kontrol fantomu normal kemik yoğunluğuna $\left(1.00 \mathrm{gr} / \mathrm{cm}^{2}\right)$ sahip olup L1-L4 vertebralardan oluşmaktadır (Şekil 1). Normal yumuşak dokuyu temsil etmek üzere fantomda fiberglas malzeme kullanılmıştır. Kemik sintigrafisi aktivitesini taklit etmek üzere Tc-99m aktivitesinin konulacağı $25 \times 35 \times 15 \quad \mathrm{~cm}$ ölçülerinde plastik malzemeden yapılmış su tankı düzeneği kullanıldı. Fantom DEXA ölçümleri Hologic QDR 4500 Elite sisteminde yapıld1.

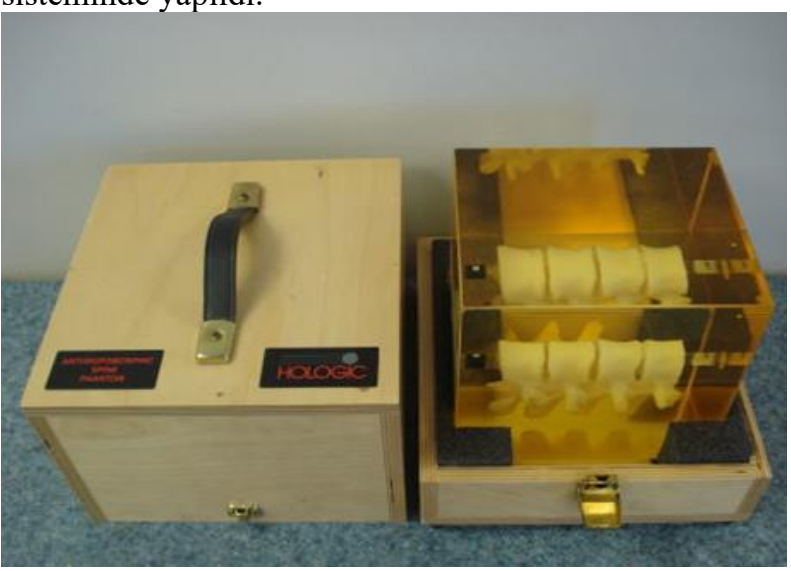

Şekil 1. DEXA Kalite Kontrol Fantomu
Gama Kamerada Sayım-Aktivite Dönüşümü

Gama kamerada sintigrafik görüntüler üzerinden çizilen ilgi alanları (ROI) içindeki sayımların karşılığı olan aktivite miktarını $\mu \mathrm{Ci}(\mathrm{MBq})$ cinsinden bulmak için bir deney düzeneği hazırlandı. Deneyin ilk aşamasında klinik kullanıma uygun miktarlarda rastgele seçilen konsantrasyonlarda $11 \mu \mathrm{Ci} / \mathrm{ml}(0.407 \mathrm{MBq} / \mathrm{ml}), 125$ $\mu \mathrm{Ci} / \mathrm{ml}(4.625 \mathrm{MBq} / \mathrm{ml})$ ve $700 \mu \mathrm{Ci} / \mathrm{ml}(25.9 \mathrm{MBq} / \mathrm{ml})$ Tc-99m radyonüklidi hazırlanarak doz kalibratöründe aktiviteleri ölçüldü. Hazırlanan solüsyonlar farklı şekillerdeki kapların içine konuldu. Siemens marka Symbia T16 SPECT/BT cihazında görüntülendi. Görüntüler Şekil 2' de görülmektedir. Bu görüntüler gama kameranın iş istasyonuna taşınarak ilgi alanları (ROI) çizildi. Böylece ROI'ler içindeki sayımlar bulundu. Dönüşüm dataları kullanılarak sayım-aktivite dönüşümü yapıldı.

Fantomun Içine Konulacak Tc-99m Aktivitesinin Belirlenmesi için Klinik Görüntü Taraması

DEXA çekimlerinde insan lomber/pelvis vücut bölgesini taklit eden fantom içindeki suya karıştırılacak olan Tc99m miktarlarının alt ve üst limitleri retrospektif olarak hasta çalışmasından elde edildi. Tc-99m MDP verilerek tüm vücut sintigrafisi çekilen ve rastgele seçilen 10 hastanın lomber/pelvis bölgelerini kapsayan alanlar seçildi. Alan içindeki toplam sayım belirlendi. Sonra belirlenen sayım miktarına karşılık gelen Tc-99m aktivite miktarı, sayım aktivite dönüşüm verilerinden yararlanılarak belirlendi. Böylece su tankına konulacak Tc-99m aktivite miktarının alt ve üst limitleri belirlenmiş oldu.

Çalışmamız İstanbul Üniversitesi-Cerrahpaşa, Cerrahpaşa Tıp Fakültesi Klinik Araştırmalar Kurulu tarafından 03.03.2020 tarihli A-32 numaralı etik kurulu onayı almıştır.

\section{Bulgular ve Tartışma \\ 3.1 Bulgular}

Şekil 2' de görülen farklı aktivite konsantrasyonlarındaki Tc-99m kaynaklarının sintigrafik görüntülerinden sayım aktivite dönüşümleri belirlendi.

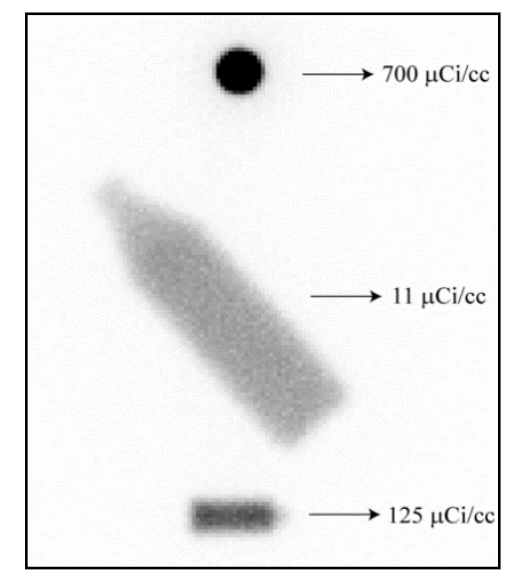

Şekil 2. Gama kamerada sayım-aktivite dönüșümü tespiti için yapılan deneyde farklı şekilde ve hacimlerde oluşturulan kalibrasyon kaynaklarının sintigrafik görüntüleri. 
Bu dönüşüm değerlerinden; ROI sayımlarının 3000000 -13000 000 arasında değiştiği görüldü. Bu sayımlara karşılık gelen Tc-99m aktivitelerinin; 0.597-4.58 mCi (22.089-169.46 MBq) arasında olduğu belirlendi. Bu datalara dayanarak, fantomdaki su tankının içine konulacak Tc-99m aktivite miktarları $0.5 \mathrm{mCi}(18.5$ $\mathrm{MBq}), 1.0 \mathrm{mCi}(37 \mathrm{MBq}), 1.5 \mathrm{mCi}(55.5 \mathrm{MBq}), 2.00 \mathrm{mCi}$ (74 MBq), $2.5 \mathrm{mCi}(92.5 \mathrm{MBq}) 3.00 \mathrm{mCi}(111 \mathrm{MBq}), 3.5$ $\mathrm{mCi}(129.5 \mathrm{MBq}), 4.00 \mathrm{mCi}(148 \mathrm{MBq})$ ve $4.5 \mathrm{mCi}$ (166.5 MBq) olarak seçildi ve uygulandi.

DEXA çekimleri ilk olarak saçılmasız hava ortamında, klinik çekim protokolüne göre yalın fantom görüntüsü alınarak yapıldı. Daha sonra fantom, içinde sadece su olan tankın üzerine konularak çekimler yapıldı (Şekil 3).

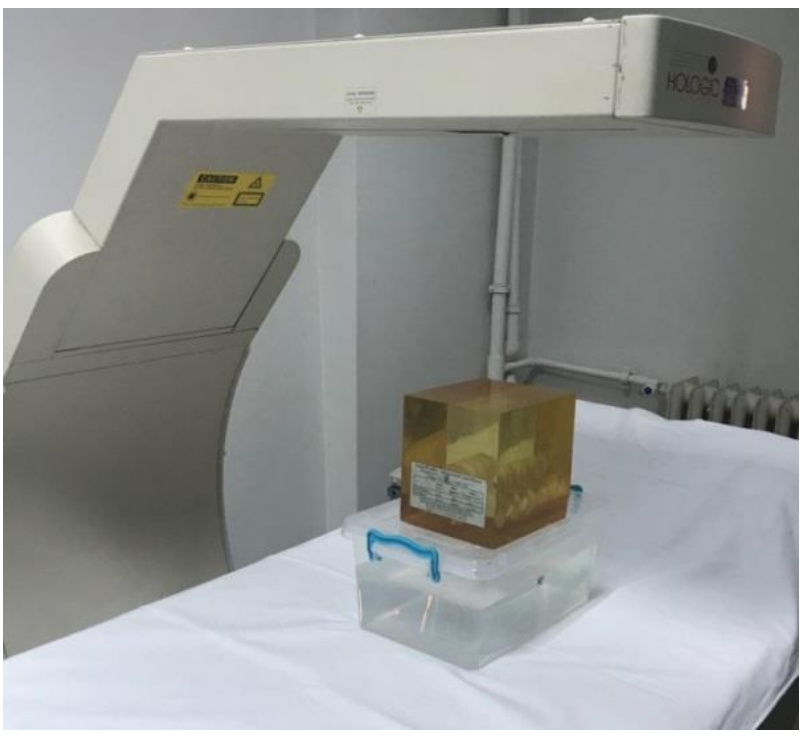

Şekil 3. KMY ölçümleri için hazırlanan standart DEXA fantom düzeneğinin hasta yatağındaki çekime hazır görüntüsü. Altta su tank1, üstte DEXA kalite kontrol fantomu.

Son aşamada ise $18.5 \mathrm{MBq}$ Tc-99m miktarı ile başlanarak ve değerleri her çekimde $18.5 \mathrm{MBq}$ artırılarak $166.5 \mathrm{MBq}$ değerine kadar sırasıyla su tankının içerisine enjekte edilip iyice karıştırıldı. Her karışımdan sonra toplamda 9 görüntü olmak üzere çekimler tamamlandı. Her bir çekimde alınan lomber vertebra (L1-L4) görüntüleri cihazın iş istasyonunda analiz edilerek KMY değerleri belirlendi. Saçılmasız ortamda alınan görüntü ve en yüksek aktivite değerinde alınan görüntüler Şekil 4' te verilmiștir.
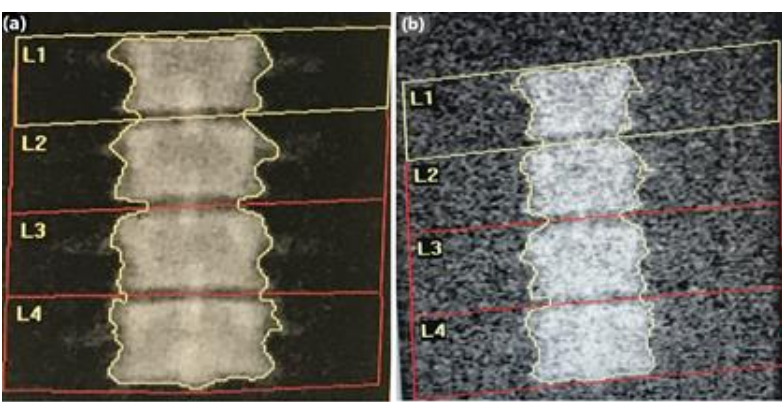

Sekil 4. DEXA kalite kontrol fantomunun çekiminden alınan lombe vertebra (L1-L4) görüntüleri. (a) Saçılmasız ortamda (b) Saçılmalı ortamda.
İki görüntü karşılaştırıldığında su ile karıştırılan Tc-99m aktivitesinin görüntü netliğini azalttığı, özellikle L1-L4 vertebra etrafinda çözünürlüğü değiştirdiği görülmektedir. DEXA kalite kontrol fantomunun KMY değerleri $1.00 \pm 0.05$ dir.

Su tankı içinde; Tc-99m olmayan 1 çekim ve seçilen toplam 9 ayrı Tc-99m aktivite değerleri uygulandı. Her Tc-99m aktivitesi etkisinde alınan DEXA çekimlerinden elde edilen L1, L2, L3 ve L4 vertebralara ait KMY değerlerine Tc-99m radyonüklidinin $140 \mathrm{keV}$ enerjili gama 1şınlarının etkisini karşılaştırmalı olarak görebilmek üzere Şekil 5 te verilen histogram eğrisi oluşturuldu.

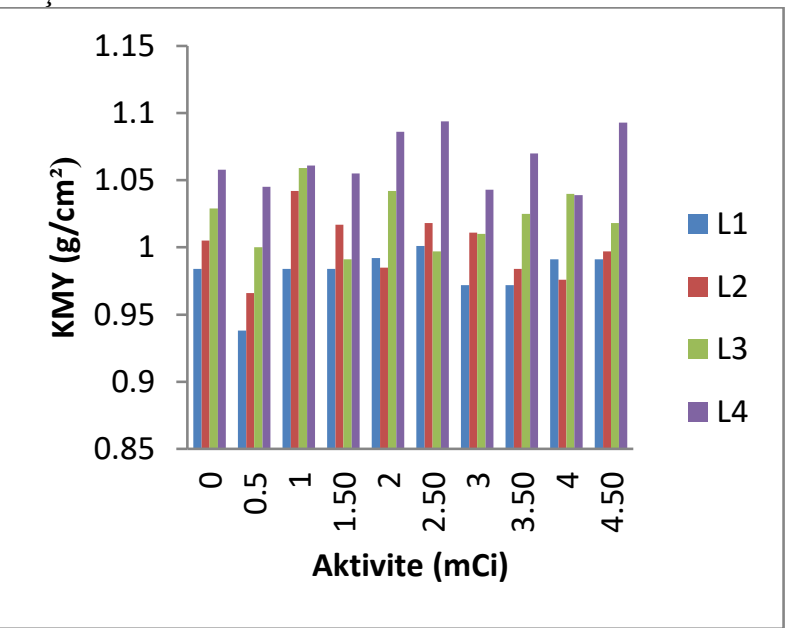

Şekil 5. 0-4.5 mCi aralığındaki Tc-99m aktivite değerlerinde alınan L1L4 vertebraların DEXA çekimlerinden elde edilen KMY değerleri.

KMY ortalama \pm SD değerleri; L1: $0.98 \pm 0.018$, L2: $1.00 \pm 0.02$, L3: $1.02 \pm 0.02$ ve L4: $1.06 \pm 0.02$ bulundu. SD değerlerinin çok küçük olduğu, bu nedenle L1, L2, L3 ve L4 KMY değerlerinin kendi içlerinde uyumlu olduğu gözlemlendi.

Saçılmasız ortamda alınan ortalama KMY değeri 1.011 $\mathrm{gr} / \mathrm{cm}^{2}$ bulundu. Bu değer referans alınarak aktiviteli ortamda alınan KMY değerlerini değerlendirmek üzere ortalama KMY-Aktivite grafiği oluşturuldu (Şekil 6).

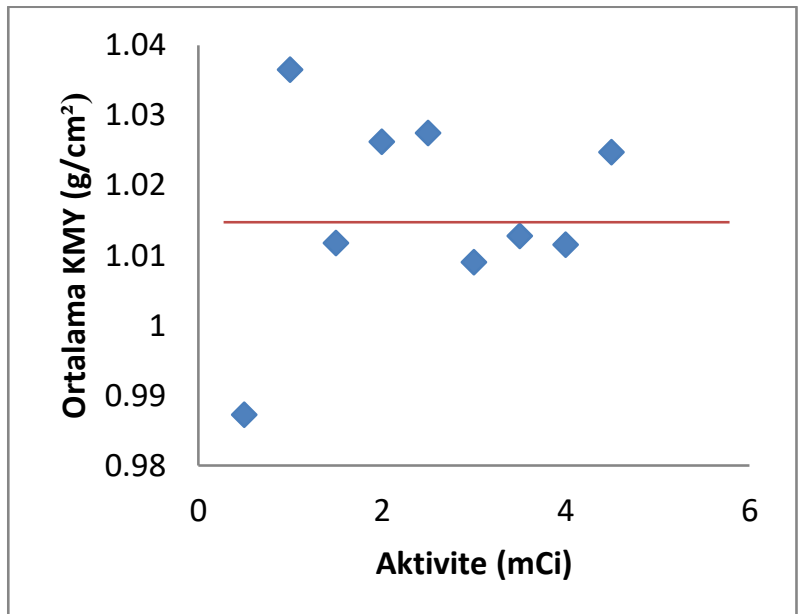

Şekil 6. L1-L4 vertebra ortalama KMY değerlerinin 0.5-4.5 mCi Tc$99 \mathrm{~m}$ aktivitelerine karşıllık değişimleri. (Kırmızı çizgi, saçılmasız ortamda alınan referans $K M Y$ değeridir). 
$\mathrm{Bu}$ grafik incelendiğinde, alınan referans değerin üzerinde dağılımın fazla olduğu altında ise sadece 18.5 MBq aktivitede alınan tek bir değer olduğu görülmektedir. $111 \mathrm{MBq}$ değerinde alınan ortalama KMY değeri ise referans değerimiz $\left(1.009 \mathrm{~g} / \mathrm{cm}^{2}\right)$ ile aynı değere sahiptir. DEXA fantomunun $1.00 \pm 0.05$ referans limit değerleri göz önüne alındığında lomber vertebraların otalama KMY değerlerinin tüm çekimlerde referans limitlerin içinde olduğu tespit edildi.

Tablo 1 incelendiğinde, hem saçılmasız hem saçılmalı ortamlarda ölçülen KMY değerlerinin referans değere yakın dağıldığı görülmektedir. L4 vertebra için ortalama KMY değerlerinin $1.065 \pm 0.021$ olduğu bulundu. L1, L2 ve L3 vertebralarının KMY değerlerinin ise referans limitleri içinde dağıldığı görüldü.

Tablo 1. Fantom DEXA Çekimlerinde farklı Tc-99m Aktivitelerinde L1-L4 Vertabraların KMY (gr/cm²) değerleri

\begin{tabular}{|l|l|l|l|l|l|l|l|l|l|l|l|l|}
\hline \multicolumn{10}{|c|}{ Aktivite Tc-99m(mCi) } \\
\hline & 0 & 0,5 & 1 & 1,5 & 2 & 2,5 & 3 & 3,5 & 4 & 4,5 & Ort \pm SD \\
\hline $\mathbf{L 1}$ & 0.984 & .938 & 0.984 & .984 & 0.992 & 1.001 & 0.972 & 0.972 & 0.991 & 0.991 & $0.98 \pm 0.01$ \\
\hline & & & & & & & & & & & \\
\hline
\end{tabular}

\subsection{Tartışma}

Liang-Jun Xie ve arkadaşları [5] yapmış oldukları bir çalışmada KMY gama ışınlarından etkilenme durumlarını araştırmışlardır. $\mathrm{Bu}$ araştırmacılar DEXA cihazında alınmış KMY ölçümlerinin Tc-99m ve I-131 radyonüklidlerinden yayılan gama işınlarından etkilenmediğini gözlemlemişlerdir.

Yıldız ve arkadaşlarının [6] yapmış olduğu hasta çalışmasında Tc-99m MDP radyonüklidinin KMY değerlerine etkisi araştırılmıştır. DEXA yöntemiyle Norland XR 46 kemik dansitometresi ile KMY değerlerini ölçmüşlerdir. 20 hasta üzerinde gerçekleştirdikleri çalışmada sintigrafi öncesi ve sonrası hastaların lomber vertebra, femur boynu, femur trokanter ve Wards alanına ait KMY değerlerinde anlamlı fark bulunmamıştır.

Campbell ve arkadaşları [7] tanısal dozdaki Tc-99mMDP radyofarmasötiğinin lomber vertebra ve femur boynuna ait KMY ölçümlerine etkisini araştırmışlardır. Hologic QDR4500 marka cihaz kullandıkları bu çalışmada Tc-99m MDP öncesi ve sonrasında alınan KMY ölçümlerinde anlamlı fark saptanmamıştır.

Meuller ve O'Connor [8] Tc-99m, I-131, Tl-201 ve Ga67 radyoizotoplarının KMY ölçümleri üzerindeki etkilerini iki farklı DEXA sistemi kullanarak araștırmışlardır. $\mathrm{Bu}$ sistemlerden biri olan Hologic QDR4500 sisteminde anlamlı fark bulamamışlardır. Lunar Prodigy sistemindeki taramalarında; Radyoizotopun KMY değerleri üzerindeki etkisinin radyoizotop kaynağının yerine, aktivite miktarına ve radyoizotopun cinsine bağlı olarak anlamlı farklılıklar olabileceğini bildirmişlerdir.

Gümüşer ve arkadaşları [9] tanısal dozdaki Tc-99m MIBI ve Tc-99m MDP radyoizotoplarının KMY ölçümlerine etkisini araştırırken DEXA çekimleri için Lunar DPXNT sistemini kullanmışlardır. Lumbar vertebradaki KMY değerlerinin bütün hastalarda azaldığını gözlemlemişlerdir. Çalışma sonunda aynı hasta için sintigrafi ve kemik dansitometresinin farklı günlerde uygulanması gerektiğini önermişlerdir.

Kemiğe metastaz yapan meme, prostat ve akciğer kanserinin yanı sıra böbrek, kolon, tiroid ve gastrik tümörler de kemiğe metastaz yapabilir [10]. Bu tür hastalara yapılan kemik sintigrafisi osteoporoz tanısında sınırlı role sahiptir [11]. Bu nedenle DEXA çekimlerine ihtiyaç duyulmaktadır [12].

Kemik sintigrafisi çekiminin ardından hastaya aynı gün DEXA yapıldığ 1 durumda KMY değerlerinin etkilenip etkilenmediğini araştıran bazı çalışmalarda; Hologic QDR4500 sisteminde radyoaktivitenin KMY değerlerine anlamlı bir etkisinin olmadığ Bizim çalışmamızın metodolojisi literatürdeki benzer çalışmalardan farklı olmasına rağmen sonuçlarımız Hologic QDR4500 sisteminde elde edilen KMY değerleri ile uyumlu bulunmuştur. Diğer sistemler kullanılarak yapılan KMY ölçümlerinin radyoaktiviteden önemli ölçüde etkilendiği belirtilmiştir $[8,9]$.

\section{Sonuç}

Çalışmamızda Tc-99m MDP nin KMY değerlerini etkilemediği saptanmıştır. Aynı gün içinde Tc-99m MDP 
tüm vücut kemik sintigrafisi çekilmiş hastaya KMY ölçümlerinin de aynı gün içinde yapılabileceği sonucuna varılmıştır.

\section{Referanslar}

1. Ersalcan, T, Özen, A, Yüksel, D, Altun, G, Öztürk, E, Balcı, T.A, Karayalçın, B, Procedure Guideline for Bone Density Measurement, Turkish Journal Nuclear Medicine, 2009, 18(1), 31-40.

2. Sindel, D, Gula, G, Osteoporozda kemik mineral yoğunluğunun değerlendirilmesi, Turkish Journal of Osteoporosis, 2015, 21 (1), 23 29.

3. Demir, M, Nükleer Tıp Fiziği ve Klinik Uygulamaları, İstanbul: AB Ofset Ankara, 2014, pp:360-364

4. Atlıhan Gündoğdu, E, Özgenç, E, Ekinci, M, Özdemir, D, Aşıkoğlu M, Radyofarmasötikler Radiopharmaceuticals Used İn İmaging and Treatment in Nuclear Medicine, Journal of Literature Pharmacy Sciences, 2018, 7 (1), 24-34.

5. Liang-Jun, X, Jian-Fang, L, Feng-Wei, Z, Hang, J, Mu-Hua, C, Yi, C, Is Bone Mineral Density Measurement Using Dual-Energy X-Ray Absorptiometry Affected By Gamma Rays? Journal of Clinical Densitometry: Assestment \& Management of Musculoskeletal Health, 2013, 16(3), 275-278.

6. Yıldız, M, Çiçek, E, Çerçi, S, Süslü, H, Özbek, M, Tc-99m-MDP nin Kemik mineral yoğunluğu Değerlerine Etkisi, Süleyman Demirel Üniversitesi Tip Fakültesi Dergisi, 2006, 13 (3), 9-11.

7. Campbell, A, McCarthy, M, Blake, M, Roff, G, Effect of Tc-99mMDP administration on dual-energy X-ray absorptiometry bone mineral density measurements, Journal of Clinical Densitometry, 2005, 8(1), 14-17.

8. Meuller, B, O'Connor, MK, Effects of radioisotopes on the accuracy of dual-energy X-ray absorptiometry for bone densitometry, Journal of Clinical Densitometry, 2002, 5(3), 283-287.

9. Gumuser, G, Parlak, Y, Topal, G, Aras, F, Ruksen, E, Sayit, E, Effects of Tc-99m MIBI and Tc-99m MDP administration on Dual Energy x-ray absorptiometry bone mineral density measurements, Nuclear Medicine Communications, 2009, 30(6), 445-446.

10. Metler, F.A, Guiberteau, M.J, Essentials of Nuclear Medicine Imaging, Cahapter 8 Skeletal System 6th ed., Elsivier Inc 2012, 274 314.

11. İlçe, H.T, Radyoaktif iyot tedavisi uygulanan hipertiroidili hastalarda kemik mineral yoğunluğunun dansitometre ile değerlendirilmesi [Tıpta Uzmanlık Tezi], Düzce, Türkiye: Düzce Üniversitesi 2009.

12. Koloni, P.F, Omedei, M.S, Nahas-Neo, J, et al., Prevalence of low bone mineral density in post menopausal breast cancer survivors, Revista Brasileira de Ginecologia e Obstetrícia, 2015, 37(1), 30-35.

13. Demir, M, Özmen, Ö, Uslu, İ, Kemik Mineral Yoğunluğu Ölçümlerine Tc-99m Tüm Vücut Kemik Aktivitesinin Etkileri, Cerrahpaşa Medical Journal, 2000, 31 (4), 196-201.

http://edergi.cbu.edu.tr/ojs/index.php/cbusbed isimli yazarın CBU-SBED başlıklı eseri bu Creative Commons Alıntı-Gayriticari4.0 Uluslararası Lisansı ile lisanslanmıştır 